ISSN 1981-416X

Licenciado sob uma Licença Creative Commons

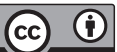

\title{
Os livros didáticos e a formação da identidade de gênero nas escolas étnicas polonesas do Paraná nos anos de 1930
}

The textbooks and gender identity training in schools polish ethnic of Parana in years 1930

Los libros didácticos y la formación de la identidad de género en las escuelas etnicas polonesas del Paraná en los años 1930

\section{Valquíria Elita Renk ${ }^{*}$}

\section{Resumo}

Este artigo se insere na História da educação. Discute o papel da escola e do livro didático na formação, na construção e conformação de uma identidade de gênero. $O$ recorte temporal são as primeiras décadas do século XX e circunscreve-se às escolas étnicas polonesas no Paraná. A pesquisa foi realizada com a análise documental do livro didático Elementarz - Dla dzieci polskich w Brasylji (Primeiro livro - Para as crianças Polonesas no Brasil), de autoria de Konstanty Lech de 1936. É um livro de alfabetização que traz os vestígios de uma concepção de educação nas escolas étnicas polonesas. Nestas escolas as moças tinham uma educação voltada para o trabalho no lar, aos cuidados com a casa e a família e os

*VER: Doutora em Educação, e-mail: valquiria.renk@pucpr.br 
rapazes para as tarefas ao ar livre nas florestas e campos. O ensino em língua polonesa era uma forma de manter a identidade étnica. A História Cultural orienta a análise do corpus documental, mostrando como o livro didático contribui na incorporação de valores sociais, atitudes e condutas, além de construir nos indivíduos uma representação deles mesmos e uma interpretação social com o mundo.

Palavras-chave: Educação. Escolas étnicas. Identidade de gênero.

\section{Abstract}

This paper is part of the history of education and discusses the role of the school and textbook in the formation, construction and conformation of a gender identity. The temporal cut is the first decades of the twentieth century circumscribes the Polish ethnic schools in Paraná. The research was carried out with the documentary analysis of the textbook Elementarz - Dla dzieci polskich w Brasylji (First book - For Polish children in Brazil) written by Konstanty Lech of 1936. It is a literacy book that brings the traces of a conception of education in ethnic Polish schools. In these schools girls had an education focused on household chores, caring for the home and family, and boys for outdoor tasks in the forests and fields. Teaching in Polish was a way of maintaining ethnic identity. Cultural History guides the analysis of the documentary corpus, showing how the didactic book contributes to the incorporation of social values, attitudes, behaviors and constructs in individuals a representation of themselves and a social interpretation of the world.

Keywords: Education. Ethnic schools. Gender identity.

\section{Resumen}

Este artículo se inserta en la historia de la educación y discute el papel de la escuela y del libro didáctico en la formación, construcción y conformación de una identidad de género. El recorte temporal son las primeras décadas del siglo XX, se circunscribe a las escuelas étnicas polacas en Paraná. La investigación fue realizada con el análisis documental del libro 
didáctico Elementarz - Dla dzieci polskich w Brasylji (Primer libro - Para los niños polacos en Brasil), de autoría de Konstanty Lech escrito en 1936. Es un libro de alfabetización que trae los vestigios de una concepción educación en escuelas étnicas polacas. En esas escuelas, las niñas tenían una educación orientada al trabajo en casa, cuidando del hogar y de la familia, y los muchachos para las tareas al aire libre en los bosques y campos. Enseñar en polaco era una manera de mantener la identidad étnica. La Historia Cultural orienta el análisis del corpus documental, mostrando cómo el libro didáctico contribuye a la incorporación de valores sociales, actitudes, comportamientos y construye en los individuos una representación de sí y una interpretación social con el mundo.

Palabras clave: Educación. Escuelas Étnicas. La identidad de género.

\section{Introdução}

Neste artigo objetiva-se discutir a construção e conformação da identidade de gênero, ensinada nos livros didáticos, nas escolas étnicas polonesas do Paraná, nos anos de 1930, em pleno período de nacionalização do ensino. No estado havia mais de 160 escolas primárias polonesas, que funcionavam à margem do aparelho escolar estatal, demonstrando a importância da escolarização da infância para este grupo étnico (WACHOWICZ, 1970). A língua polonesa era um elemento da identidade étnica, para muitos membros deste grupo étnico, era considerada como a língua materna e, também, era ensinada nas escolas.

A infância das crianças de descendência polonesa ${ }^{1}$ era marcada pela escolarização nas escolas étnicas, pela vivência comunitária nas colônias e pela iniciação no trabalho no espaço familiar e na agricultura. A infância é compreendida como uma etapa da vida, construída histórica

1 Por crianças polonesas entendem-se os filhos dos imigrantes poloneses, mesmo que nascidos no Brasil, se identificavam etnicamente como polonesas e não como brasileiras. Os poloneses e seus descendentes são entendidos como um grupo étnico, na acepção de Barth (1969). 
e socialmente (VEIGA, 2004; SOUZA, 2010; BELLONI, 2009). Algumas instituições foram fundamentais para a manutenção dos valores culturais, como as escolas, as associações instrutivas e a Igreja Católica.

Este artigo se inscreve na perspectiva da História da Educação. As fontes de pesquisa trazem os indícios fundamentais para responder os questionamentos propostos e possibilitam ao pesquisador o entendimento do objeto de pesquisa, a dimensão do tempo, sua relação histórica e sociocultural (LE GOFF, 1984, FARGE, 2009, CORSETTI e LUCHESI, 2010, PESAVENTO, 2004). O corpus documental é formado pelos Relatórios de Governo do período analisado e pelo livro didático Elementarz - Dla dzieci polskich w Brasylji (Primeiro livro - Para as crianças Polonesas no Brasil), de autoria de Konstanty Lech, publicado em $1936^{2}$, pela Editora Oswiata, vinculada à Igreja Católica. Os livros didáticos trazem indícios do processo escolar de formação da identidade de gênero e na manutenção da identidade cultural étnica. A História Cultural orienta a análise do corpus documental, com Chartier (1990, 2001, 1995), Certeau (1994), Julia (2001) e as relações entre os gêneros são analisados por Louro (1997, 2001, 2014).

\section{Família, escola e ethos do trabalho}

O Paraná é um estado pluriétnico e recebeu aproximadamente 57 mil imigrantes poloneses desde o final do século XIX até o ano de 1948 que em sua maioria formavam as colônias étnicas determinadas pelo governo (WACHOWICZ, 1970). Aproximadamente $80 \%$ das famílias eram camponesas, tinham muitos filhos e viviam do trabalho familiar em pequenas propriedades rurais. Neste sentido, a família, a escola, a rede de sociabilidades, as associações culturais e a igreja foram fundamentais para a conservação da língua do país de origem e a manutenção da identidade étnica nas colônias. Os grupos étnicos criam critérios

2 O livro é publicado em preto e branco, em língua polonesa. Está divido em lições e cada uma traz imagens ilustrativas. Konstanty Lech foi professor e autor de vários livros didáticos em língua polonesa. 
para auto-atribuição de pertencimento étnico e a etnicidade é como um "idioma" no qual são comunicadas as diferenças culturais nos contextos de interação com outros grupos étnicos (BARTH, 1969, POUTIGNAT; STREIFF-FERNAT, 1998, CUNHA, 1986).

Os descendentes de imigrantes poloneses adotavam a identidade polonesa de pertencimento étnico, sendo chamados de polacos ${ }^{3}$ mas, não negavam a cidadania brasileira. A língua polonesa era considerada por muitos como a língua materna. A língua portuguesa era falada por poucos e era usada mais frequentemente para se comunicar fora da colônia, especialmente nas relações com os brasileiros. Neste sentido, a identidade étnica só existe em um sistema de oposição, definida por diferenciados contextos culturais e históricos, onde vive o indivíduo (ORIOL, 1986, HALL, 2003, BARTH, 1969). Portanto, cabia também à escola a manutenção da identidade étnica com o ensino em língua polonesa.

O trabalho era parte da identidade camponesa, entendido como um referencial de virtudes e um valor social para os descendentes de poloneses. As referências ao trabalho dos imigrantes europeus tornaram-se um contraponto da própria imagem do trabalhador nacional, eram considerados como trabalhadores, com disciplina para o trabalho livre e portadores dos elementos de civilização (KOWARICK, 1994). Era um elemento de contraste em relação aos brasileiros, que eram representados como signo "da doença, do vício, da falta de vitalidade, da degradação e da degenerescência. O trabalho é, nessas figurações, elemento ausente da vida nacional” (CARVALHO, 1989, p. 10).

O trabalho como valor social era ensinado às crianças desde a tenra infância. Era executado pela família "na lavoura e venda de produtos, entre o homem, a mulher e os filhos menores. Os filhos desde pequenos começam a participar das atividades dos pais" (HORBATIUK, 1989, p. 43). Portanto, a infância das crianças descendentes de poloneses tinha

3 Octávio lanni, em Raças e Classes no Brasil (1966) constata os preconceitos vividos por homens e mulheres descendentes de poloneses em Curitiba e registra o preconceito da população, ao afirmar que em Curitiba "não há negros. O negro do Paraná é o polaco" (p. 131). 
curta duração e o tempo era dividido entre a escola e as obrigações com o trabalho em casa e na propriedade. A iniciação ao trabalho era entendida pelas famílias como parte da formação do caráter. Os documentos oficiais indicam que o governo conhecia a existência do trabalho infantil: "O filho do colono ${ }^{4}$ [...] que logo aos 7 annos já leva o almoço ao pae, quando não capina ou puxa [...] e toca os animaes no pasto. [...] toda essa infância, tão cedo amadurecida para o trabalho [...]" (PARANÁ, 1921, p. 12, grafia original). Portanto, o trabalho era parte do processo de socialização das crianças descendentes de poloneses.

Ao formar as colônias étnicas polonesas, o grupo construía de início uma igreja, uma escola e o cemitério. "Onde surge uma colônia, com sua igrejinha de torre ponteaguda, ao lado de um cemitério [...] pode ter a certeza de encontrar uma escola e quase sempre duas, funcionando das 8 às 12 ou das 12 às 16h. [...]. Onde há casas há uma escola" (PARANÁ, 1923, p. 8-12, grafia da época). Este relato oficial mostra a importância da religiosidade e a da escolaridade para as crianças, pois em praticamente cada comunidade polonesa havia uma escola étnica ${ }^{5}$. Devido à falta de escolas públicas, as comunidades construíam as suas escolas, criavam as associações escolares (sociedade-escola), providenciavam e pagavam o professor e o material didático. Como analisa Vincent, et al. (2001), para ter acesso a qualquer tipo de saber escolar é necessário dominar a língua escrita, daí a importância que este grupo étnico atribuía à escolarização das crianças.

A escolaridade era um elemento de diferenciação com os brasileiros, além de contribuir para que não fossem vistos apenas como trabalhadores pobres e ignorantes (RENK, 2014). No Paraná, em 1937, havia 167 escolas étnicas polonesas (em maioria eram escolas primárias), sendo

4 Colono é uma expressão que designa o agricultor e também o morador das colônias étnicas (SEYFERTH, 1982).

5 No Brasil o número de escolas étnicas era bastante expressivo em 1938: havia 1.579 escolas alemãs, 396 escolas italianas, 349 escolas polonesas, 178 escolas japonesas e 60 escolas ucranianas. Como estas escolas existiam à margem do aparelho estatal, estes números são aproximados e coletados em documentos oficiais, descrições de religiosos e consulados. 
137 laicas (que eram administradas pelas associações ou não) e 30 religiosas $^{6}$. Nestas, o ensino era ministrado em língua polonesa ou bilíngue (em português e polonês) sobre a história e cultura da Polônia (WACHOWICZ, 1970). Neste sentido, a língua é uma expressão da etnicidade e sua perda, significa perder a identidade étnica (CUNHA, 1986). Os livros didáticos escritos na língua de origem do grupo eram um instrumento a mais na manutenção da identidade étnica. A partir de 1918 o governo estadual começou a exigir que as escolas étnicas seguissem o Programa Oficial de Ensino e outras medidas que faziam parte do processo de nacionalização das escolas étnicas, porém, estas construíam formas de burlar, como o bilinguismo (RENK, 2014).

Nas famílias de origem polonesa os papéis sociais eram bem definidos: os homens trabalhavam na roça e negociavam a produção agrícola, enquanto as mulheres também labutavam na roça, faziam as atividades domésticas e cuidavam dos filhos. Em Curitiba, muitas moças polonesas se empregavam como criadas nas casas das famílias urbanas e recebiam parcos salários. Em menor quantidade, também buscavam o trabalho fabril urbano, fugindo da condição de ser camponesa (BUENO, 1997). À noite, em casa, as mulheres costuravam e remendavam as roupas, enquanto as moças faziam o enxoval, tornando este um tempo útil. Manter as mãos ocupadas era uma forma de disciplinar e tornar o corpo dócil, como analisa Miguel (1997). O espaço doméstico era um espaço de iniciação das meninas nas tarefas consideradas "femininas".

6 Muitas sociedades-escola tinham dificuldades financeiras em manter com regularidade as escolas em funcionamento, então, solicitavam a vinda das Congregações para assumir a educação, assim como também para neutralizar a influência de lideranças laicas progressistas. As associações culturais laicas ou religiosas mantinham as escolas, tinham bibliotecas ambulantes nas colônias, produziam jornais e livros didáticos na língua polonesa. 


\section{A construção das identidades de gênero e o livro didático}

As relações entre os gêneros foram historicamente construídas, assim como os papéis sociais atribuídos aos homens e mulheres. Assim, "não existe a condição feminina e a condição masculina. São muitos os jeitos e as possibilidades de ser homem e de ser mulher, dependendo dos fatores sociais [...]" (LOURO, 2014, p. 38). A família tem um papel importante na educação das crianças e nos padrões culturalmente aceitos para os diferentes gêneros. Desta forma, ao masculino é atribuída a representação de racionalidade, o cérebro, a neutralidade, o controle e ao feminino, a emoção, a sensibilidade, a passividade, o coração e o descontrole (CARVALHO; TORTATO, 2009). Muitas representações dos valores de identidade de gênero foram naturalizadas pela família, pela escola e pela igreja, que introjetaram práticas sociais para conformar homens e mulheres em seus papéis. Neste sentido, Roger Chartier (1995) explica que a noção de representação coletiva autoriza articular melhor o conceito de mentalidade e sua relação com o mundo social. Ele aborda que o trabalho de classificação e separação produz as configurações intelectuais múltiplas pelas quais a realidade está contraditoriamente construída pelos diferentes grupos que formam a sociedade e que as práticas tendem a reconhecer uma identidade social.

Historicamente, as sociedades e os grupos sociais construíram modos diversos de lidar com o tempo, o espaço, o corpo, a sexualidade e a educação. No ambiente escolar, a construção social dos gêneros foi "naturalizada" através de atividades pedagógicas, esportivas e estéticas. Através dos processos de vigilância e controle, a escola foi moldando os comportamentos, os movimentos corporais e as atitudes para construir os corpos de meninos e meninas (LOURO, 2014, 1997). Neste sentido, a "escola e a escolarização foram desenvolvidas até se tornarem essenciais na produção e reprodução de nossas formações sociais, das hierarquias, das classes [...] que as constituem" (VINCENT, et al. 2001, p. 38).

Nas relações entre os gêneros, Durán (2007) analisa que os trabalhos de cuidar e limpar, ainda hoje são executados em maior número por mulheres, no espaço doméstico e fora dele. O cuidado tem um objeto 
essencial que é o outro e a atenção às suas necessidades, tais como a alimentação, a limpeza, a higiene, a cura das enfermidades e o alívio do sofrimento (CALLADO, 2006). Portanto, a responsabilidade e a ética do cuidado, são construções sociais, internalizadas desde a infância pelas meninas, como analisa Gilligan (2011, p. 22) "Em meio a uma estrutura patriarcal, o cuidado é uma ética feminina”. Considera-se que a experiência feminina está relacionada com o ciclo da vida, com o cuidado maternal e neste sentido, as mulheres desenvolvem uma abordagem moral voltada para o cuidado e as responsabilidades. "Porquanto, gênero consiste em um processo de interpretação da realidade cultural, a qual se apresenta carregada de sanções, tabus e prescrições. A identidade de gênero é construída durante toda a vida do ser humano" (SANTOS; FARIAS, 2009, p. 92).

No livro didático analisado nesta pesquisa, a identidade de gênero é representada pelas ações, pelo espaço e pelas roupas usadas pelos sujeitos. As mulheres usam saias, vestidos e aventais. As meninas brincam e cuidam das bonecas, aprendem as tarefas domésticas, evidenciando o trabalho doméstico. Os homens usam terno, calças compridas e os meninos brincam e caçam na mata e usam o sabre. Isto revela como o processo de socialização escolar que cria a cultura escolar e produz interpretações da realidade (VINCENT et al. 2001, MOLERO PINTADO, 2000, JULIA, 2001). Neste sentido, a seleção de um livro didático como fonte de pesquisa é significativa, pois o pesquisador "atribui um sentido novo às palavras que tira do silêncio dos arquivos" (CHARTIER, 2001, p. 171).

\section{A importância dos livros didáticos na educação escolar}

No Brasil a adoção de livros didáticos data da época do Império. A República deu continuidade ao processo de uniformização do ensino na construção da nação. Razzini (2005, p. 107) analisa que os livros didáticos foram importantes, pois "iriam construir a ideia de pátria moderna e civilizada, ou seja, conteúdos que combinavam temas patrióticos, regras de civilidade e índices de modernidade e progresso". 
Os livros didáticos apresentam-se de forma muito particular como manuais de estudos, devendo ter conteúdos, linguagem e um público a que se destinam. Neste sentido, Pesavento (2004, p. 42) analisa que a proposta da História Cultural é de "decifrar a realidade do passado por meio das suas representações, tentando chegar àquelas formas, discursivas e imagéticas, pelas quais os homens expressam a si próprio e o mundo". Assim, os livros didáticos podem ser considerados dispositivos educativos, pois neles estão inscritas as imagens, os discursos, as práticas e as representações sociais produzidas em certo período. E o que está contido nele acaba transformando-se, na maioria dos casos, "o status de verdade absoluta, imutável e inquestionável” (CASAGRANDE; CARVALHO, 2009, p. 109). São instrumentos de transposição didática dos saberes acadêmicos que precisam inscrever-se em um ambiente pedagógico específico e inserir-se nos campos disciplinares do ensino. A transposição didática é uma forma de inteligibilidade para que o saber acadêmico, decorrente do avanço das pesquisas científicas, seja ensinado aos estudantes na educação básica (CHEVALLARD, 1991).

Considerando que o livro didático contribui para homogeneização dos sujeitos e dos saberes, deve-se considerar que o Estado tem importante papel social neste processo, pois, "molda as estruturas mentais e impõe princípios de visão e de divisão comuns" (BOURDIEU, 2010, p. 105). Nas décadas de 1920-1930, o governo foi prescrevendo outras medidas com o propósito de nacionalização da infância nas áreas de imigração, como a obrigatoriedade do ensino em Língua Nacional, as aulas de História e Geografia do Brasil, o Canto Orfeônico, a adoção dos livros didáticos prescritos (em língua nacional e especialmente de Língua Portuguesa, História e Geografia do Brasil), a comemoração das datas cívicas e as aulas de Educação Física (RENK, 2014) ${ }^{7}$. Apesar disto, taticamente como analisa Certeau (1994),

7 Em muitas escolas étnicas a doção do bilingüismo foi uma tática de sobrevivência (CERTEAU, 1994), pois as aulas eram ministradas em um período na língua materna do grupo e no outro período na língua nacional. Assim, ao mesmo tempo, as escolas ministravam as aulas de História e Geografia do Brasil, adotavam os livros didáticos prescritos. Esta forma de ensino dificultava a fiscalização por parte do governo, visto que, as escolas não descumpriam a legislação, mas, ao mesmo tempo ensinavam em/na língua materna do grupo. 
as escolas étnicas mantiveram o uso dos livros didáticos escritos na língua materna como uma das expressões da manutenção da identidade cultural e da resistência ante o processo de nacionalização.

\section{Apresentando o livro didático Elementarz - Dla dzieci polskich w Brasylji}

Neste artigo são analisados oito textos do livro didático Elementarz - Dla dzieci polskich w Brasylji (Primeiro livro - Para as crianças Polonesas no Brasil, 1936 - tradução livre) publicado pela Editora Oswiata $^{8}$, sediada em Curitiba, vinculada à Congregação Vicentina. Esta Congregação religiosa era importante no Paraná, pois mantinha inúmeras escolas étnicas polonesas para meninas e meninos, além de um seminário para formação de padres e professores em Curitiba. Não é possível saber sobre a circulação deste livro, porém, algumas fontes indicam que era adotado nas escolas laicas e religiosas.

$\mathrm{O}$ autor K. Lech ${ }^{9}$, era professor e autor de livros didáticos. Ele tinha grande representatividade na comunidade étnica e falava de um lugar social, o de ser professor. O fato de seu livro ser publicado pela Editora Oswiata demonstra seu prestígio social ante a Igreja Católica e a concordância com teor dos conteúdos dos seus livros didáticos. Assim, pelo fato deste livro ser publicado por uma editora vinculada a uma Congregação Religiosa, pode-se deduzir que os saberes ali informados não eram neutros,

8 A Oswiata era uma Associação Cultural vinculada à Igreja Católica do Paraná e teve grande influência na manutenção das escolas étnicas religiosas, em oposição à Associação Kultura, laica que também influenciou a criação e manutenção de escolas étnicas polonesas. Estas duas Associações disputavam o espaço nas comunidades com a criação de escolas étnicas, associações culturais e produção de jornais em língua polonesa.

9 O Professor K. Lech ministrou aulas em 1925 e fez parte da Diretoria do Colégio Henrique Sienkiewicz em Curitiba (em polonês): Língua Polonesa, História da Polônia, Geografia, Polônia Contemporânea, Geometria, Álgebra, Física e Química. Este era um colégio na região central de Curitiba e diferenciava-se de outras escolas primárias por sua estrutura pedagógica e corpo docente. Para saber mais: <http://www.sociedadepolonesakosciuszko.org/pag/sociedade/spbtk10.html>. 
mas, saberes que foram "dominados e confiscados pelos indivíduos ou instituições que se arrogam o controle exclusivo sobre eles" (CHARTIER, 1991, p. 180).

O livro analisado neste artigo foi publicado em $1936^{10}$, em pleno período de nacionalização das escolas étnicas no Paraná e no Brasil. Desde 1900 (Lei n. 365 de 11/04/1900), a legislação escolar do Paraná enfatizava a obrigatoriedade de o ensino ser ministrado em língua nacional. Naquele período, a publicação de livros didáticos em língua estrangeira não era proibida, mas, poderia ser interpretado como um ato de resistência da Igreja Católica através da Associação Oswiata e das escolas étnicas ante a política de nacionalização.

Era um livro de alfabetização escrito em língua polonesa, destinado às crianças na faixa etária de seis ou sete anos. O livro é dividido em lições com imagens, textos e, às vezes, exercícios. Inicia com a escrita das letras, dos fonemas, a formação de sílabas, de palavras até os pequenos textos. Os temas abordados são a família, as brincadeiras, o cotidiano, o ambiente rural, o trabalho, a religião católica e a cultura da Polônia. É importante considerar que o leitor faz a sua interpretação do que é lido e isto também produz sentidos em sua vida. Neste sentido, concorda-se com Chartier (1991, p. 15, 17) que através dos livros "em diferentes lugares e momentos, uma determinada realidade social é construída, pensada, dada a ler". Considerando que foi escrito no Brasil, em 1936, em pleno período de nacionalização e de discussão da formação da população, este livro não apresenta a diversidade étnica racial brasileira, pois as crianças representadas neste livro são todas de pele branca, asseadas, higienizadas e usam sapatos. Apesar do livro analisado não explicitar, os textos e imagens estavam em concordância com as teses eugênicas que circulavam naquele período (D’AVILA, 2006).

${ }^{10} \mathrm{O}$ livro foi publicado dois anos antes do fechamento das escolas étnicas no Brasil, através do Decreto Federal 406 de 04/05/1938. Também podem ser citadas as leis que versavam sobre a obrigatoriedade do ensino em língua nacional e das aulas de História e Geografia do Brasil, a saber: Decreto n. 93 de 11/03/1901, Lei Estadual n. 723 de 03/04/1907, Lei n. 894 de 19/04/1909, Código de Ensino do Paraná de janeiro de 1917, Lei 2005 de 09/04/1920, Decreto Lei 2.157 de 1922 até culminar com o fechamento das escolas étnicas em todo o país com o Decreto Federal 406 de 04/05/1938. 
As famílias apresentadas neste livro didático são constituídas por pai, mãe e filhos. As relações familiares são ilustradas no livro analisado com imagens dos pais segurando os filhos nos braços, os irmãos brincam juntos, as mães cuidam da família demonstrando atitudes de proteção, cuidado e atenção. Neste sentido, a naturalização da forma e comportamentos familiares permite inferir que a "forma escolar de relações sociais é a forma social constitutiva do que se pode chamar de uma relação escritural-escolar com a linguagem e com o mundo" (VINCENT, el al. (2001, p. 35). Pode-se intuir que estas imagens contribuíram para construir representações sobre a responsabilidade social e moral da família ao incutir valores, condutas e, ao mesmo tempo produzir e conformar os corpos dos meninos e das meninas. Desta forma, Chartier (1991) nos convida a refletir como a leitura constrói nos indivíduos uma representação deles mesmos e uma interpretação social do mundo.

O trabalho é representado em imagens de cenas doméstica e da vida rural. São apresentadas as propriedades rurais com vacas pastando no cercado, com cavalos e potros pastando. As mulheres em trabalho doméstico ou sobre a carroça carregada de feno sendo puxada por cavalos, a propriedade rural cercada de jardim, as mulheres zelando pela vida familiar usando aventais, a menina lavando e estendendo as roupas, entre outras. Portanto, um texto que compartilha os mesmos bens culturais por diferentes grupos sociais que compõem uma sociedade, legitima novas recepções, cria novos públicos e novos usos (CHARTIER, 1995, p. 60). Isto legitima o livro didático com um dispositivo pedagógico. A familiaridade com o espaço rural e o trabalho no campo mostra que a iniciação para o trabalho era ensinada na família e na escola. Portanto, a proximidade com certas imagens e linguagens objetivaram interiorizar nos escolares determinados conteúdos que "conquistaram sua coerência na/pela escrita" (VINCENT, et, al. 2001, p. 29).

As imagens dos textos deste livro trazem vestígios sobre as representações dos papéis masculinos e femininos para este grupo étnico, pois, apresentam as meninas usando saias, vestidos, aventais, brincando com bonecas, lavando roupas e semeando flores, fazem referência, em sua maioria, 
ao espaço e trabalho doméstico, como a casa e o quintal (DURÁN, 2007, LOURO, 2014). "Os códigos linguísticos e representações culturais que caracterizam o gênero feminino são aspectos importantes para se compreender a identidade da mulher [...] é extremamente importante para as análises sobre a forma como os livros didáticos as apresentam" (PEREIRA, 2013, p. 14).

As imagens dos meninos, os mostram vestindo bermudas, andando a cavalo, brincando ao ar livre, desbravando florestas, remando canoas nos rios. Estas coisas, que representavam atitudes e valores como a valentia e a bravura. Neste sentido, a escola ao adotar o livro didático também educa, inculca valores e conforma os corpos dos jovens e das crianças (MEYER, SOARES, 2004, LOURO, 2014).

\section{A formação da identidade de gênero feminina nas lições do livro didático}

Analisar um livro didático é olhar como as fontes documentais guardam os vestígios da cultura escolar. Neste sentido, concorda-se com Dominique Julia (2001), que analisa o papel social da escola em estabelecer normas, definir conhecimentos, ensinar condutas, inculcar práticas e comportamentos que irão reverberar na vida dos sujeitos além do período escolar. A atuação da escola extrapola os muros, pois tem uma "ampliada atuação social na medida em que [...] produz, divulga e legitima identidades, competências e modos de vida, ao mesmo tempo em que deslegitimam outros" (FARIA FILHO; BERTUCCI, 2009, p. 14). Neste livro analisado, as imagens e os textos ensinaram saberes e também contribuíram para moldar comportamentos.

A seguir serão analisados alguns textos selecionados que evidenciam o processo de formação da identidade de gênero feminina.

O texto intitulado Basia, refere-se a uma menina pequena, assim denominada, que está aprendendo a falar e que tem uma boneca por ela amada. Na narrativa do texto, seu irmão Bolek não gosta de bonecas, mas, prefere brincar com o sabre de madeira. Neste texto evidenciam-se os brinquedos e as brincadeiras como elementos de formação da identidade 
de gênero. Os meninos e as meninas constroem suas identidades à medida que são identificados social e historicamente, como masculinos ou femininos (LOURO, 2014, CARVALHO; TORTATO, 2009).

O texto Lucia refere-se a uma mocinha que está semeando as flores no jardim. Ela usa um avental sobre o vestido e está ajoelhada, trazendo as representações do grupo sobre o trabalho feminino no cuidar (da casa) (CALLADO, 2006). A narrativa do texto é que em breve será verão, o jardim ficará florido e perfumado com as flores que Lucia plantou e a imagem traz a representação da identidade de gênero feminino e de uma menina virtuosa. Seyferth (1982) analisa que entre os descendentes de imigrantes no Brasil valorizava-se muito a mulher que tinha um belo jardim e horta. Neste sentido, a imagem e o texto trazem em si uma autoridade de sentido que permite que o leitor internalize os conteúdos e as práticas sociais representadas (CERTEAU, 1994).

A iniciação da menina aos trabalhos domésticos pode ser conhecida na lição Pranie (Lavar roupas - tradução livre). Este texto aborda sobre a atividade de lavar roupas, usando sabão para fazer espuma, enxaguar e estender no varal, como pode ser observado na Figura 1.

Figura 1 - Ilustração de livro didático: Menina lavando roupas

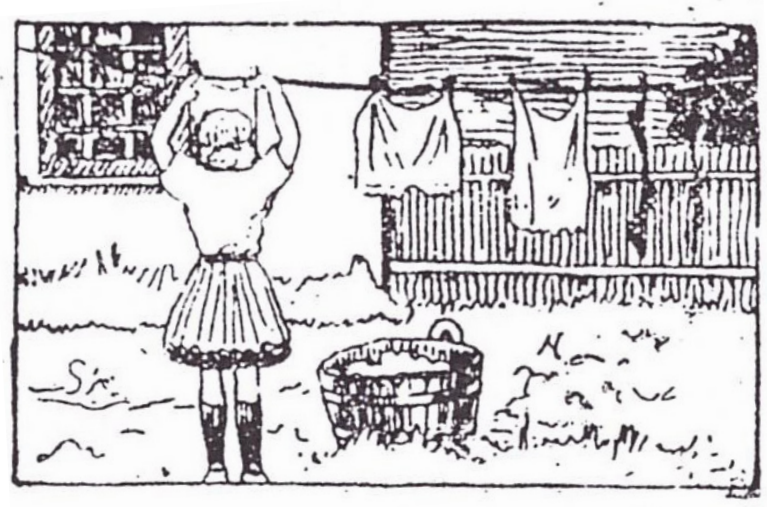

Fonte: LECH, K. Elementarz - Dla dzieci polskick w Brazulji, p. 86, 1936. 
A Figura 1 ilustra uma menina estendendo as roupas no varal, tendo a cesta de roupas ao chão, no quintal da casa. Embora o texto não faça inferências diretas que lavar roupas era um trabalho feminino, a ilustração traz esta representação. Associa-se às tarefas de cuidar, limpar, como atributos historicamente definidos como femininos (DURÁN, 2007, CARVALHO; TORTATO, 2009). Uma das formas de diferenciar a educação de meninos e meninas nas escolas primárias do Paraná eram as aulas de Trabalhos Manuais ${ }^{11}$, como parte integrante do Programa Oficial de Ensino. Neste sentido, pode-se analisar que o livro didático ao inserir uma imagem, traz uma representação de realidade, está ensinando condutas e comportamentos (JULIA, 2001).

A internalização do cuidado com a saúde pode ser conhecida no texto Choroba lalki (Bonecas doentes - tradução livre). A menina narra que sua boneca está doente e que precisará de um médico para tratá-la, como demonstrado na Figura 2.

Figura 2 - Bonecas doentes - ilustração de brincadeira no livro didático

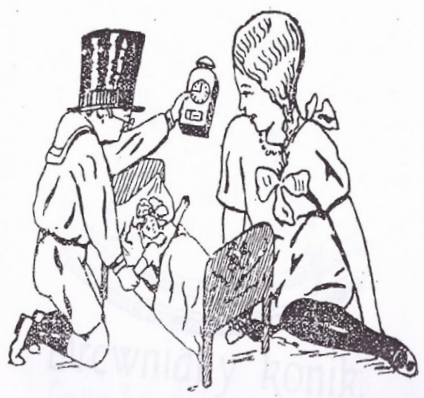

Fonte: LECH, K. Elementarz - Dla dzieci polskick w Brazulji, p. 83, 1936.

${ }^{11}$ Os Decretos 1.874 de 29 de julho de 1932 e Decreto 9.592 de 26 de fevereiro de 1940, prescreviam os conteúdos a serem ministrados nas aulas de Trabalhos Manuais, em todos os anos do ensino primário no Paraná. 
A imagem representa uma menina sentada no chão, junto ao berço da boneca, ao seu lado está um menino segurando o pulso da boneca e um relógio (o gesto apresenta semelhanças com a forma de mediar à pulsação). A menina trata a boneca como uma filha, cuidando da sua "doença". Embora o texto não mencione, as atividades de cuidar e tratar são reportadas ao gênero feminino e o papel do médico, ao gênero masculino, como afirma Scott (1995, p. 86) que o gênero é uma "forma primária de dar significação às relações de poder". Chartier (1995) analisa que representações e práticas como as divisões do mundo social são incorporadas pelos indivíduos em seus pensamentos e suas condutas.

\section{A construção da identidade de gênero masculina}

A construção da identidade de gênero masculina é apresentada em alguns textos e ilustrações do livro analisado. Como exemplo, pode-se citar o texto sobre o menino Tadek. Neste, há uma descrição da paisagem e como ele entra e desbrava a floresta, até sair numa clareira ao lado do rio. Ele veste bermudas, camisa, traz um objeto na mão, e está na margem do rio. Assim, o ato de desbravar a floresta pode ser entendido como uma atitude de valentia e ousadia, em referência ao gênero masculino. A educação escolar, como analisa Louro (2001), contribui na formação e conformação dos corpos, neste caso, tendo valores sociais como referência.

No texto Dyzio (este era o nome do menino), os meninos vestem bermudas, calças compridas, usam sapatos e meias, trazem bastões nas mãos e estão em ambiente de campo aberto. As imagens fazem referência aos atributos masculinos, como a valentia, o enfrentamento e o destemor (CARVALHO; TORTATO, 2009, LOURO, 2014). Assim, quando o menino Dyzio declama para seus amigos sobre marchar nas montanhas e nos vales enfrentando os desafios, ele está apresentando os objetos, as formas, os códigos e as normas culturais aceitas para o gênero masculino (CHARTIER, 1995, LOURO, 2014). 
Outro exemplo é o texto sobre o menino Pequeno João. Ele está sorridente, veste uma camisa, calça remendada, traz consigo um brinquedo, fazendo referências ao período da infância (tempo de brincar) até o dia de ir para a escola. Portanto, o livro didático traz referências de uma infância socialmente reconhecida, do tempo de ser criança (VEIGA, 2004, SOUZA, 2010) por outro lado, pode-se analisar que a escola se constitui em um espaço de controle do corpo e de disciplina do sujeito (FOUCAULT, 2013).

Os meninos também são representados nas lições como pessoas cuidadosas com os irmãos menores e com as irmãs. As relações fraternais entre os irmãos estão descritas nos textos intitulados Henio i Helenka (Henry e Helena - tradução livre) e Rys i Rózia (Rys e Rosi - tradução livre), Felek i Franus (que são irmãos), onde as crianças brincam ao ar livre de esconde-esconde, vão à floresta caçar pássaros e brincam de cavalo. Estes textos mostram que a infância é uma idade social, onde as crianças externam a alegria de brincar e a convivência fraternal. Evidenciam-se os referenciais de identidade de gênero masculina, como a força e a proteção das irmãs e irmãos menores. Neste sentido, "os dispositivos formais (textuais ou materiais) inscrevem em suas estruturas as expectativas e as competências do público" (CHARTIER, 1995, p. 186). Estas lições revelam também a introjeção de valores sociais e morais como elementos da cultura escolar.

Neste livro didático analisado, as crianças tinham uma formação cívica polonesa. A lição Kto ty jestes? (Quem é você? — Tradução livre) é ilustrada com a Águia Branca, símbolo da Polônia, aborda sobre a identidade étnica polonesa e termina com a seguinte frase: "Nós somos polacos porque falamos polonês". Este texto identifica a importância da língua na manutenção da identidade étnica e a resistência em adotar uma identidade brasileira. Discute-se com Michel de Certeau (1994) sobre as práticas e as formas de fazer dos sujeitos no espaço escolar, pois, de forma tática as escolas continuavam ensinando a cultura de origem do grupo, em pleno período de nacionalização escolar. Portanto, as escolas étnicas criaram mecanismos para manter a identidade cultural, entre eles, o uso do livro didático em língua polonesa. Portanto, como analisa Chartier (1991, p. 10) não se pode ignorar "o processo pelo qual um texto, uma 
fórmula, uma norma, fazem sentido para os que dele se apoderam ou se apropriam". Esta lição, em especial, registra o processo de resistência cultural por parte deste grupo étnico em manter o ensino na língua de origem do grupo. Também permite compreender as tensões estabelecidas com o Estado no processo de nacionalização escolar, lembrando que, desde a década de 1920, o Inspetor de Ensino do Paraná reclamava do pouco progresso do aprendizado da língua nacional nas escolas étnicas. "A língua falada é a polonesa. Nosso idioma é inteiramente desconhecido por essas populações, cujos filhos aqui nasceram” (PARANÁ, 1920, p. 23). Afirmava ele que estar numa escola étnica era como estar em outro país.

As fontes de pesquisa revelam vestígios da cultura escolar nas escolas étnicas polonesas. Nesta pesquisa, o livro didático analisado revelou como os textos e as imagens engendram em si as representações dos papéis sociais, das formas de pensar e agir socialmente na construção das identidades de gênero. O livro analisado traz indícios sobre a circulação dos saberes no espaço escolar e sua contribuição para formar homens e mulheres a desempenhar seus papéis sociais de acordo com as expectativas sociais na sociedade em que estavam inseridos.

\section{Considerações finais}

A maioria das famílias de imigrantes poloneses do Paraná era camponesa, vivendo em pequenas propriedades, produzindo com o trabalho familiar, ensinando às crianças o trabalho como um valor social. A escolarização dos filhos era muito valorizada, sendo a escola um espaço de manutenção da identidade étnica com aulas na língua polonesa ou de forma bilíngue.

A análise das fontes possibilitou compreender a construção escolar do ethos do trabalho, do respeito aos outros, das relações fraternais entre irmãos e amigos, que eram apresentadas como modelos a serem seguidos. As famílias representadas nos textos analisados são nucleares, compostas por pai, mãe e filhos. $O$ valor do trabalho é ensinado às meninas na sua relação com o trabalho doméstico, como lavar roupas e cultivar jardins, enquanto 
para os meninos são ensinadas atividades nos campos e florestas, representando valentia e bravura. O livro didático analisado traz vestígios que mostram como a escola encontrava formas de fazer, na perspectiva de Certeau.

A escola era um espaço de conformação de corpos e das identidades de gênero, ao ensinar os papéis sociais de meninos e meninas, que eram naturalizados nas lições dos livros didáticos. Nos textos analisados encontram-se vestígios de como a educação escolar conformava os corpos de meninos e meninas. As fontes foram de grande importância para se conhecer como a cultura escolar naturalizava os atributos considerados femininos e masculinos. Além disso, o trabalho de cuidar, limpar, administrar a casa e a família é atribuído às moças para que aprendessem a ser donas de casa e mães zelosas, inculcando-se a ética da responsabilidade e do cuidado desde a tenra idade às meninas. Na educação escolar formavam-se os corpos, condutas e comportamentos socialmente aceitáveis ao gênero masculino, como brincar e realizar atividades em espaços ao ar livre, desbravar as florestas e atravessar rios e campos.

A narrativa dos textos analisados contribui para compreender a construção escolar dos corpos e dos gêneros, reafirmando as representações socialmente aceitas. Os fundamentos teórico-metodológico da Histórica Cultura e, mais especificamente, o estudo da Cultura Escolar, mostraram que os livros trazem os saberes para ensinar e os saberes a ensinar, ancorados em uma dada realidade educacional socialmente construída.

\section{Referências}

BARTH, F. Etnic groups and boundaries. London: Geoge Allens and Unwin, 1969.

BELLONI, M. L. O que é sociologia da infância. Campinas: Autores Associados, 2009. BOURDIEU, P. Razões práticas sobre a teoria da ação. Campinas: Ed. Papirus, 2010. 
BUENO, W. de L. Um olhar sobre a diferença: polacas ou polonesas em Curitiba. In: TRINDADE, E. M. de C. et. al. (org). Mulheres na História. Paraná- séculos 19 e 20. Curitiba: Editora UFPR, 1997.

CALLADO, M. J. G. Mujeres y Resiliencia. In: MIGUEL, P. De. Espiritualidad e fortaleza feminina. Bilbao: Desclée de Brouwer, 2006.

CARVALHO, M. G; TORTATO, C. de S. B. Gênero: considerações sobre o conceito. In: LUZ, N. S. da; CARVALHO, M. G. de; CASAGRANDE, L. S. Construindo a igualdade na diversidade: gênero e sexualidade na escola. Curitiba: Editora UTFPR, 2009.

CARVALHO, M. M. C. A escola e a República. São Paulo: Brasiliense, 1989

CERTEAU, M. de. A invenção do cotidiano: As artes de fazer. Petrópolis: Vozes, 1994.

CHARTIER, R. El mundo como representación. Estudos sobre História Cultural. Barcelona: Gedisa Editorial, 1995.

CHARTIER, R. Cultura Escrita, Literatura e História. Porto Alegre: Artmed, 2001.

CHARTIER, R. A história cultural entre praticas e representações. Rio de Janeiro: Bertrand Brasil; 1990.

CHARTIER, R. Uma crise da história? A história entre narração e conhecimento. In: PESAVENTO, S. J. (Org). Fronteiras do milênio. Porto Alegre: Ed. UFRGS, 2001. p. 115-140.

CHEVALLARD, Y. La Transposition Didactique. Grenoble: La Pensée sauvage, 1991. CUNHA, M. C. da. Antropologia do Brasil. São Paulo: EDUSP; Brasiliense, 1986.

D’AVILA, J. Diploma de brancura. Política social e racial no Brasil - 1917-1945. São Paulo: UNESP, 2006.

CORSETTI, B.; LUCHESE, T. A. Educação e instrução na Província do Rio Grande do Sul. In: GONDRA, J. G.; SCHNEIDER, O. (Org.). Estado e instrução nas províncias e na corte imperial. Vitória: EDUFES, 2010. p. 453 - 485.

FARGE, A. O sabor do arquivo. São Paulo: EDUSP, 2009. 
DURÁN, M. Á. El valor del tiempo: Cuántas horas te faltan al día? Espanha: Espasa, 2007.

FARIA FILHO, L.M; BERTUCCI, L. M. Experiência e cultura: contribuições de E. P. Thompson para a história social da escolarização. Currículo sem fronteiras, v. 9, n. 1, p. 10-24, jan./jun. 2009.

GILLIGAN, C. Joining the Resistance. Cambridge: Polity Press, 2011.

HALL, S. Da diáspora: identidades e mediações culturais. Belo Horizonte: Ed. da UFMG, 2003.

HORBATIUK, P. Imigração Ucraniana no Paraná. Porto União: Uniporto, 1989.

JULIA, D. A cultura escolar como objeto histórico. Revista Brasileira de História da Educação, Campinas, n. 1, p. 9-43, 2001.

KOWARICK, L. Trabalho e vadiagem a origem do trabalho livre no Brasil. São Paulo: Paz e Terra, 1994

LECH, K. Elementarz. Dla dzieci polskich w Brazylji. Curitiba: Oswiata, 1936.

LE GOFF, J. A Nova Historia. Lisboa: Edições 70, 1984.

LOURO, G. L. O corpo educado: pedagogia da sexualidade. Belo Horizonte: Autêntica, 2001.

LOURO, G. L. Gênero, sexualidade e educação. Petrópolis: Editora Vozes, 2014.

LOURO, G. L. Mulheres na sala de aula. In: PRIORE, M.D. (org). História das Mulheres no Brasil. São Paulo: Contexto, 1997.

MEYER, D. E.; SOARES, R. de F. R. (orgs). Corpo, gênero e sexualidade. Porto Alegre: Mediação, 2004.

MIGUEL, M. E. B. A formação do professor e a organização social do trabalho. Curitiba: Editora UFPR, 1997. 
MOLERO PINTADO, A. En torno a la cultura escolar como objeto histórico. In: RUIZ BERRIO, J. (Org.). La cultura escolar de Europa: tendencias históricas emergentes. Madrid: Biblioteca Nueva, 2000.

ORIOL, M. Quelquers propositions théoriques pour l'analyse dês identités culturelles. In: DAVIDOVIC, D; KUZMANOVIC, D. L'identité culturelle dês jeunes migrants yougoslaves em France. Paris: Beogard: s.n., 1986.

PARANÁ. Relatório apresentado ao Secretário Geral do Estado, pelo Professor César P. Martinez em 1920. Curitiba: DEAP, 1920.

PARANÁ. Relatório apresentado ao Secretário Geral do Estado, pelo Professor César P. Martinez em 1921. Curitiba: DEAP, 1921.

PARANÁ. Relatório apresentado ao Secretário Geral do Estado, pelo Professor César P. Martinez em 1923. Curitiba: DEAP, 1923.

PEREIRA, A. M. A representação da mulher no livro didático de História. Monografia (Especialização em Educação) - Universidade Tecnológica do Paraná (UTFPR), 2013. Disponível em: <http://repositorio.roca.utfpr.edu.br/jspui/bitstream/1/4496/1/MD_EDUMTE_2014_2_113.pdf. Acesso em: 17 jun. 2017.

PESAVENTO, S. J. História \& História Cultural. 2. ed. Belo Horizonte: Autêntica, 2004. POUTIGNAT, P.; STREIFF-FENART, J. As teorias da etnicidade. São Paulo: Fundação Editora da UNESP, 1998.

RAZZINI, M. de P. G. Livros e leitura na escola brasileira do século XX. In: História e memórias da Educação no Brasil. v. II. Século XX. Petrópolis: Vozes, 2005.

RENK, V.E. As escolas étnicas polonesas e ucranianas no Paraná. Curitiba: Appris Editora, 2014.

SANTOS, S. F; FARIAS, B. G. F. Gênero, Educação e Artefatos tecnológicos: Os diferentes meios para ensinar. In: Construindo a Igualdade na Diversidade: gênero e sexualidade na escola. 22. ed. Curitiba: UTFPR, 2009. 286 p.

SCOTT, J. Gênero: uma categoria útil de análise histórica. Educação e realidade, v. 20, n. 2, p. 71-99, jul./dez. 1995. 
SEYFERTH, G. Nacionalismo e Identidade étnica: a ideologia germanista e o étnico teuto-brasileiro numa comunidade do Vale do Itajaí. Florianópolis: FCC, 1982.

SOUZA, G. de (org). Educar na Infância. Perspectivas histórico-sociais. São Paulo: 2010. VEIGA, C. G. Infância e Modernidade. In: FARIA FILHO, L. (org). A infância e sua educação: materiais, práticas e representações. Belo Horizonte: Autêntica, 2004. VINCENT, G. et al. Sobre a História e teoria da forma escolar. Educação em Revista, Belo Horizonte, n. 33, p. 7-47, jan. 2001.

WACHOWICZ, R. (org). As escolas de colonização polonesa no Brasil. Anais da Comunidade Brasileira Polonesa. Curitiba: Volume II, 1970.

Recebido: 11/12/2018

Received: 12/11/2018

Recibido: 11/12/2018

Aprovado: 24/07/2018 Approved: 07/24/2018 Aprobado: 24/07/2018 